\title{
Image, Precariousness and the Logic of Cultural Production in Hong Kong
}

\section{Carolyn Cartier, University of Technology Sydney}

The time of Hong Kong continues to pose dilemmas. The idea of 1997, the year of the transfer of sovereignty over Hong Kong from Great Britain to the People's Republic of China (PRC), would mark the end of the British colonial era. From 1997 to 2046, Hong Kong is officially a Special Administrative Region (SAR) of the PRC. On July 1, 2046, it will become regular territory of the PRC. Thus the SAR would never become independent and would exist outside the logic of postcolonial time and space that has characterized former colonies throughout the world. The SAR would also raise an enduring question: would the change in sovereignty over Hong Kong result in replacing one colonial power with another? Hong Kong would not enter the post-British era by forming independent state institutions and locally generated nationalism as a basis of postcolonial identity formation. There would be no national self-determination. The director of the Hong Kong Art Centre at the handover, Oscar Ho, evaluated the context and the relationship between identity formation and artistic practice: "places where art really flourishes are those where there are urgent issues that art needs to deal with. And pre-'97 there were definitely some very clear and strong issues that needed dealing with, ones having to do with the concept of identity: Hong Kong's relationship with China, the colonial legacy, and how to position oneself with China and the British" (Ho 2005: $10-11)$.

In reflecting on Oscar Ho's observations, this discussion about culture and the city reconsiders ideas about the possibilities of postcoloniality and the politics of culture in Hong Kong. To discuss these issues, I introduce the street art calligraphy practice by 
Tsang Tsou-choi, known as the 'King of Kowloon,' and the stenciled likenesses of Ai Weiwei by graffiti artist Tang Chin, known as Chin Tangerine. Neither of these projects takes the visual form of graffiti in the conventional sense of 'tagging' (Manhattan subway cars) or sanctioned alternative art in 'blank' urban spaces (murals under highway overpasses). Whether identified as graffiti, street art or cultural work, their projects take material form in the city, circulate as images in diverse media, and enfold multiple representations about postcoloniality, territoriality, political authority and cultural difference - the dilemma of 'Hong Kong in China.' Their further capacity to engage, challenge and provoke, within the local and national political economy, and, ultimately, to transcend 'the local' and become entrained within the world art system, arguably identifies the significance of precariousness in Hong Kong and its logic of cultural production.

The idea that cultural projects in Hong Kong reflect and demonstrate aesthetics of postcoloniality is not new, yet the limits of past formulations have become clearer with shifts in the post-1997 landscape. In this essay I suggest the need for new contexts of understanding cultural activity and fresh readings of their symbolic and relational meanings in political and economic terms. In the next section, I compare theoretical perspectives on cultural production in the city to demonstrate why we may wish to clear some ground for alternative and new interpretations, especially for alternative art works and cultural projects in Hong Kong engaged with social issues and political change. The reality is that the compelling 1997 'identity question' has receded from central debate with the emergence of increasingly challenging issues. Reprising Oscar Ho's words, some new clear and strong issues need dealing with, especially after 2003, when historic local protests stopped implementation of the PRC's national 'security law,' seeking controls on freedom of expression; and 2005-2006, when income inequality in Hong Kong, the highest among developed economies, became a sustained public issue.

\section{Postmodernity, postcoloniality, contemporaneity}

The scholarship on the question of postcoloniality in Hong Kong demonstrates a range of topics and theoretical approaches (see, for example, Tam 1997; Erni 2001, 2012; Fung 2004; Lo 2005; Henderson 2008; Lu 2009), among which the most well known in the international academy is the work in film studies and postmodern theory. In this arena, the title Hong Kong: Culture and the Politics of Disappearance (Abbas 1997), a 
treatment of Hong Kong cinema, exquisitely captured the anxieties of 1997 and gained influence beyond its field. Its core argument holds that the problem of postcolonial identity in Hong Kong is misleading: the real question is rather 'subjectivity in a space of disappearance' and understanding that 'postcoloniality is a tactic and a practice, not a legal-political contract or a historic accident' (Abbas 1997: 10). With this formulation, Abbas showed the problems of thinking about the postcolonial as a historical time, and persuasively demonstrated the multiple, complex and positional conditions of identity. In treating the postcolonial as a question about the potential limits of understanding identity, 'culture and the politics of disappearance' turned a phrase on the handover and refracted images of the city whose future could only be imagined.

Yet for anyone concerned with the realities of the politics of cultural production and daily life in the city, the notion of 'subjectivity in a space of disappearance' (Abbas 1997: 10) should yield some pause: what 'space' and what conditions of 'disappearance'? In its dedication to the visual, and working through postmodern linguistic turns, such as "using disappearance to deal with disappearance" (7-8), the text conveys how understanding Hong Kong at the handover, and Hong Kong identity, cannot be achieved through fixed or limited representations. ${ }^{1}$ Yet the linguistic formulation slips between representations and realities of the city, between film space and urban space: 'the way the city has been made to appear in many representations in fact works to make it disappear' (7). This slippage points to the incommensurability of using film space to understand urban space: in reality, the city cannot 'in fact' disappear. Inspired by Paul Virilio's The Aesthetics of Disappearance (1991), such critical inquiry based in visual studies captured the uncertain aesthetics of rapid change in Hong Kong, yet the fundamentally postmodern theoretical line - working through film text rather than material space - bracketed realities of the urban process and remained at an incommensurable distance from the realities of daily life. It reproduced Jane Jacobs' (1996) caution about delineating the postcolonial at some level of postmodern

\footnotetext{
${ }^{1}$ The 'Hong Kong handover' refers to the change of sovereignty over Hong Kong from Great Britain to the People's Republic of China, which took place on 1 July 1997. The handover is also used as the English-language translation of 香港回归祖国 (Xianggang huigui zuguo), Hong Kong's return to the motherland, which is often shortened simply to 回归 (huigui, return). In the general sense, the hand-over refers to the time before and after 1997 but there is no set period of years defining the handover. The once common phrase 'in the run-up to 1997 ' or 'in the run-up to the handover' characterized the late colonial period and came into use after London and Beijing signed the Joint Agreement, in 1984, that defined the terms and planning process for the change of sovereignty. To say 'at the time of the handover' is to indicate the year 1997, and 'around the handover' may include up to two to three years before or after, but again there is no specified time span.
} 
theoretical abstraction, finding culture in signs and texts, divorced from history and political economy.

The 'urban process' indicates the development and restructuring of urban space under late or advanced capitalism (1970s to the present), in which the increasing pace of the turnover time of capital causes rapid change in the built environment. An example in Hong Kong is the Ritz-Carlton, 1993-2008, a high-rise hotel in Central District that was demolished after only 14 years to rebuild the site with an office tower to achieve higher rents. Increasing pace in the turnover time of capital also applies to households and daily life, in which many people work longer hours to achieve more and higher value consumption, which is required to fuel postindustrial economies. The situation contributes to economic inequity since people in low-paying jobs especially must work longer hours or multiple jobs to participate. With their concentrated mix of low wage and high wage jobs, world cities lie at the crossroads of these economic forces. Yet politically, no other major city in the world lives within the complex and contending national and transnational histories of Hong Kong.

Hong Kong cinema dates to the middle of the twentieth century and was enriched by film companies that left Shanghai with the advance of the Communist regime in 1949 (Fu 2003). By comparison, contemporary and alternative art emerges in Hong Kong in the late twentieth century, closely associated with international currents in art practice and overseas training. Alternative and political art in Hong Kong enters a period of unprecedented expansion with 1997, with its focus on exploration of Hong Kong identity. The first monograph on the subject, Hong Kong Art: Culture and Decolonization, by David Clarke (2001), records contemporary work produced at the handover, especially installation art and alternative performance art. 'Hong Kong Incarnated: Museum 97,' a work by Oscar Ho, is the emblematic exhibit of the era. It featured a mythical history of Hong Kong in the body of 'Lo-ting,' a proto-historical man-fish - a population generated from the sea - a Hong Kong that could not be descendent from the empire of the yellow earth (a metaphor for China). 'Museum 97' retrieved the place of Hong Kong from a subsidiary role in the history of nation-states

\footnotetext{
${ }^{2}$ The metaphor 'yellow earth' indicates the historic cultural hearth of China in the Wei River valley, a tributary to the Yellow River in north China. It also symbolizes the idea of China as a settled agricultural society by contrast to the maritime and inner Asian frontier regions. The color yellow directly refers to the eroded soil of the loess plateau, in north central China, which forms the sediment load of the Yellow River.
} 
and centralized its significance, showing how myth works in any nation-building experience (Clarke 2001; Ngan \& Lai 2004).

Ever since, the image and idea of 'Lo-ting' has circulated in the arts and culture community in Hong Kong. Such a postcolonial approach to cultural production has created of a set of new symbolisms indexed to place that represent collective identity. Yet such 'localness' also challenges notions of 'provincialism': to produce art in Hong Kong without referencing or reproducing the canonic traditions of 'Chinese art,' especially ink painting, is to challenge or put aside essential ideas about Chinese aesthetics and art practice and, by extension, the 'Chineseness' that it represents. By dealing with the complexity of identity in Hong Kong, contemporary art addresses a suite of themes associated with anti-essentialist positions. It problematizes meanings of Chinese identity, including recognizing how different perspectives matter. Reflecting these understandings, I Like Hong Kong ... Art and Deterritorialization, by Frank Vigneron (2010), maintains the local perspective that there is no 'Hong Kong art'; rather, art in Hong Kong must be contextualized to understand its meanings and contributions to public culture.

In these ways, the time and space of cultural production in Hong Kong occupies transitory territory and locates its 'precariousness' - in lack of readily definitive status and uncertain future. Its measures emerge in postcolonial approaches that locate the problems of national frames - nationalizing histories and art histories of the national. Artworks outside the national frame question linear narratives of history from a singular, authoritative worldview and they project alternatives. They often sketch the 'ordinary unseen' through images of local understandings that prevail irrespective of the elite-led state-capital urban process. Such projects also locate contradictions and hypocrisies embedded in state ideological frameworks that would work to circumscribe and limit the interests of average people, while maintaining social and economic inequalities.

Since the mid-2000s, with the shelving of the national 'security law' under Article 23 of the Hong Kong Basic Law, I argue that the problem of identity in Hong Kong has recomposed and rescaled in a politics of aesthetics - the politics of what can be made visible and sayable - concerned with the place of Hong Kong in the nation. Such a political aesthetic cannot yield to the clichéd 'East meets West' of Hong Kong's commercial discourses or the postmodern's flattened history in a 'pastiche' of fast- 
moving images. Reframing the Hong Kong cultural landscape depends on understanding how the problem of identity re-emerges in contemporary politics of articulation, an aesthetics of politics that 'invents ways of being, seeing and saying, engenders new subjects, new forms of collective enunciation' (Corcoran 2010: 7). Such potential forms of cultural production contribute to what Jacques Rancière calls the 'redistribution of the sensible which defines the common of a community, to introduce into it new subjects and objects, to render visible what had not been, and to make heard as speakers those who had been perceived as mere noisy animals' (2009: 25). It follows that the redistribution of the sensible in time and space also holds the potential to render visible different possibilities of cultural production.

Rancière in fact speaks more about the political than art, not least because 'contemporary art is, quintessentially, art defined by the erasure of medium specificity, indeed by the erasure of the visibility of art as a distinct practice' (2007: 1). This condition of the contemporary aesthetic regime of art, that is, 'artists' or cultural workers working with multiple media and wearing different hats, informs understanding integrated relationships between art and daily life in the urban sphere, and the potential of critical and alternative artworks to comment on and intervene in social and economic problems of the global city.

\section{Cultural projects, art works}

Within these perspectives, I turn to examine an episode in cultural production in Hong Kong through two simultaneous but unconnected events: the 2011 exhibit, 'Memories of King Kowloon,' marking the lifetime of the public calligraphy or calligraphy graffiti work by Tsang Tsou-choi (1921-2007), and the graffiti imaging of the likeness of Ai Weiwei in Hong Kong, during his detention in Beijing in April 2011, by Tang Chin. As graffiti works, they are alternative art forms — street art—linked by their production on surfaces of the built environment in public space. They differ in form, style and performative approach and, ultimately, in reception in the city. In each case, I do not treat these cultural productions in the normative sense of art history, that is, establishing 'facts' about these artists because their works, in step with the thought of Rancière, exist outside the conventions of the world art system's efforts to establish provenance and biography for commercial valuation. 
As cultural projects, I find that the work of Tsang Tsou-choi and Tang Chin both represent deeply rooted yet precarious meanings about culture and the possibilities of Hong Kong identity, meanings of identity that transcend the prolonged moment of 1997. After 40 years of daily life practice, in which he was alternately disregarded, avoided, arrested and ultimately admired, the work of Tsang Tsou-choi has been 'discovered' and adopted within the art system. The work by Tang Chin featuring images of $\mathrm{Ai}$ Weiwei was new in 2011, and met by stepwise reaction through photographic documentation, media and Internet circulation, rapid removal by municipal workers and police investigation. Tang Chin herself hid in the context of producing the work. Within social and political norms in Hong Kong, both projects represent some measure of deviancy and aberrant conduct, yet one has been ultimately commodified while the other has been alternately hailed and criminalized. In each project, meanings about identity emerge in cultural practice and context, in spaces of daily life in the city.

\section{Tsang Tsou-choi}

The large-scale retrospective exhibit of the work of Tsang Tsou-choi, 'Memories of King Kowloon,' appeared at ArtisTree from April 20 to May 31, 2011 (Figure 1). ArtisTree is an art space ('multi-purpose venue') opened in 2008 at Island East, a corporate office and hotel complex owned by Swire Properties, part of a conglomerate that originated as a nineteenth-century British trading house. The gallery site alone, embedded inside the privatized space of one of Hong Kong's leading property firms, jars with Tsang Tsou-choi's life history as a person with diminished mobility living on social assistance. In his practice of working and living days on the street, Tsang painted a modern, blocky calligraphy on remnants of the urban landscape, especially pillars, construction walls and utility boxes (Figures 2 and 3). The ArtisTree exhibit was distinctive for its size and design, and reach into the material culture from Tsang's daily life such as brushes, ink bottles and an old ID card, in addition to documenting the history of his work (Figure 3). We must have critical reactions to the presentation style of the exhibit for its extraordinary contrast to Tsang's daily life practice and production on the street (Figure 4). For example, the cost of mounting even one large object under glass would have likely sustained Tsang and his family for a week.

The story of the 'King of Kowloon' is well known in Hong Kong. His works have been widely documented in local art criticism and in several exhibits, beginning in 1997. His 


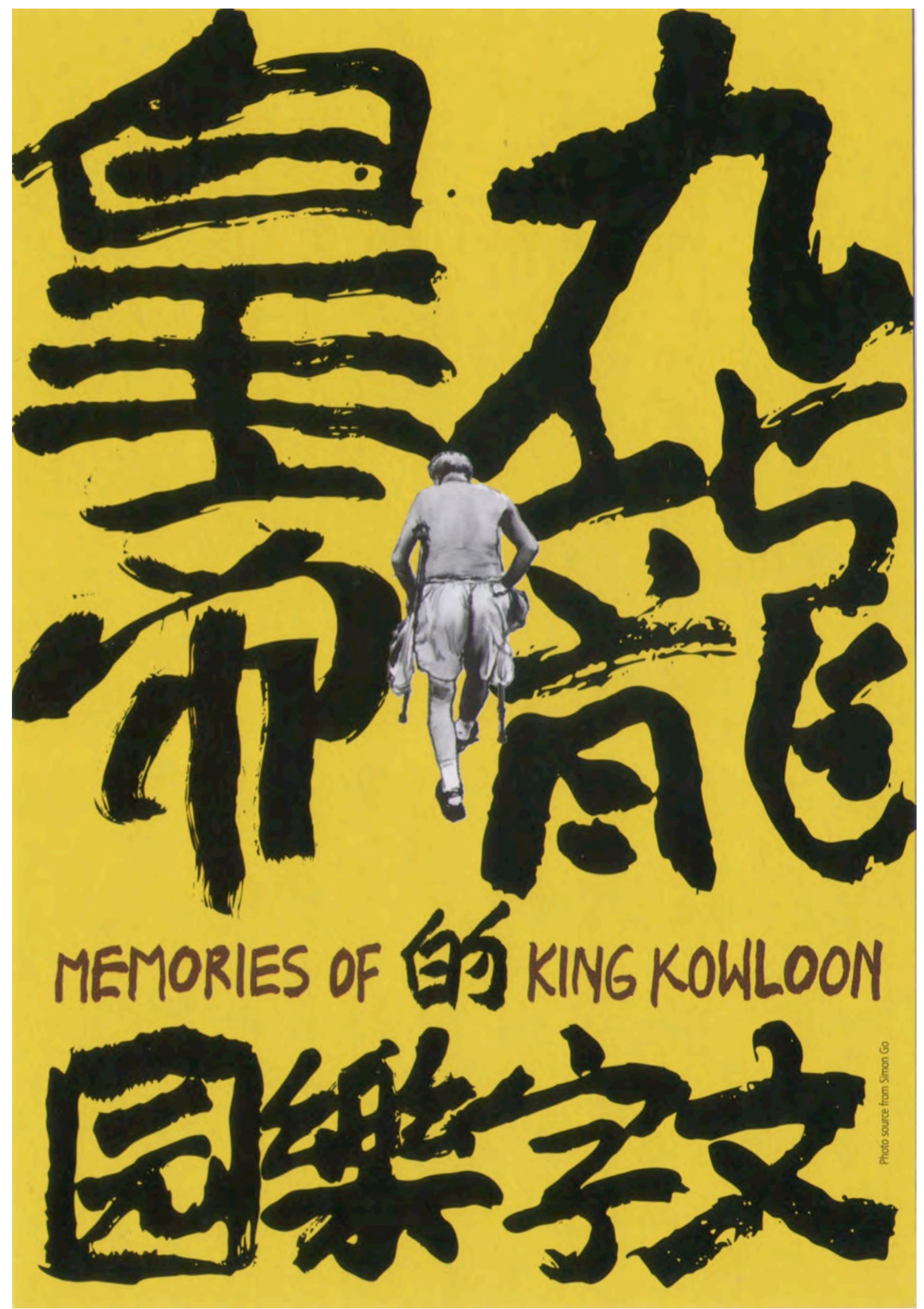

Figure 1. Exhibition card, 'Memories of King Kowloon.'

ArtisTree, 20 April-31 May 2011, Hong Kong. 


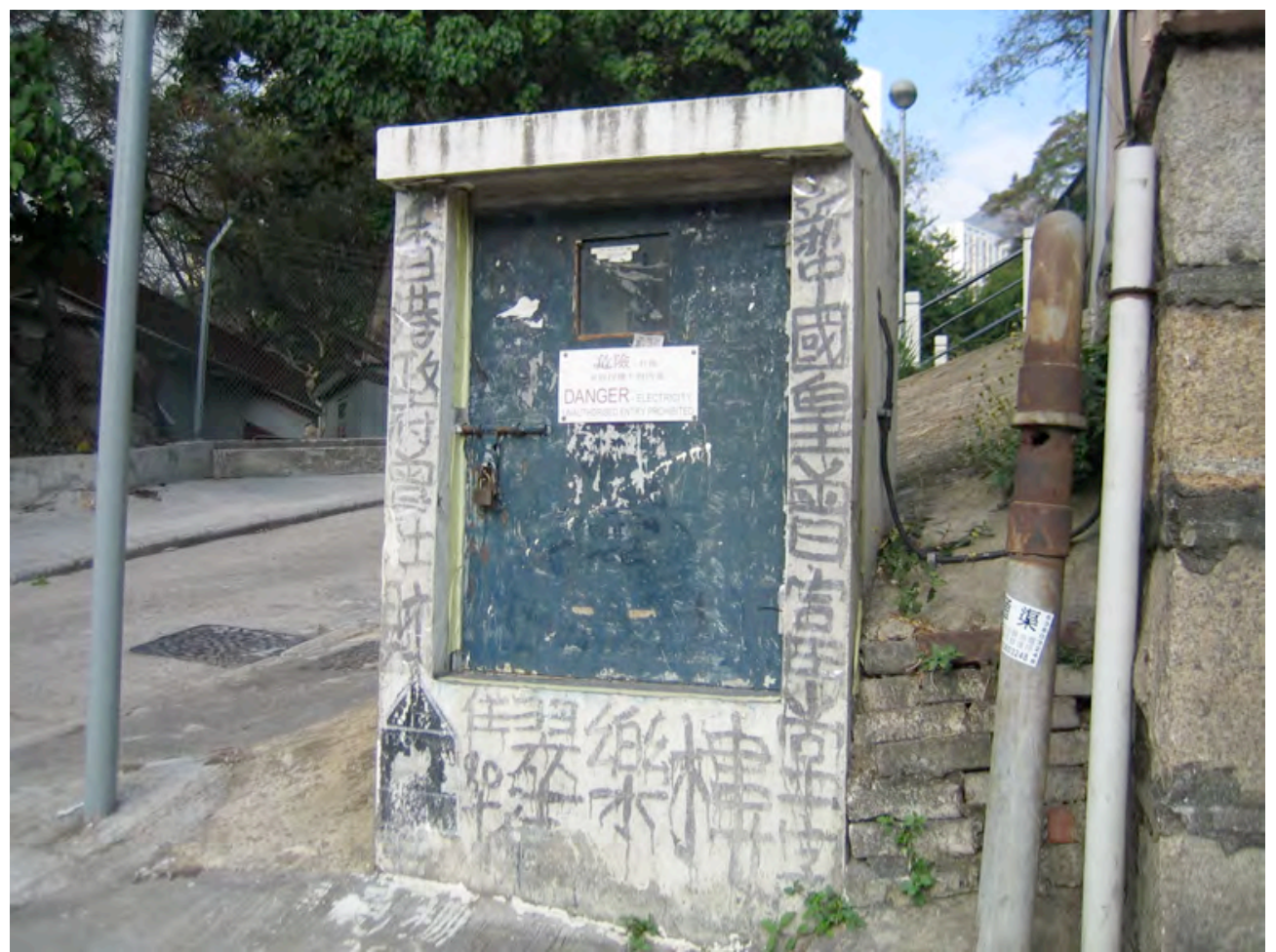

Figure 2. Tsang Tsou-choi's calligraphy on utility box, roadside adjacent to Kwun Tong Children's Playground, Kwun Tong, Hong Kong. 19 December 2010. Wikimedia Commons.

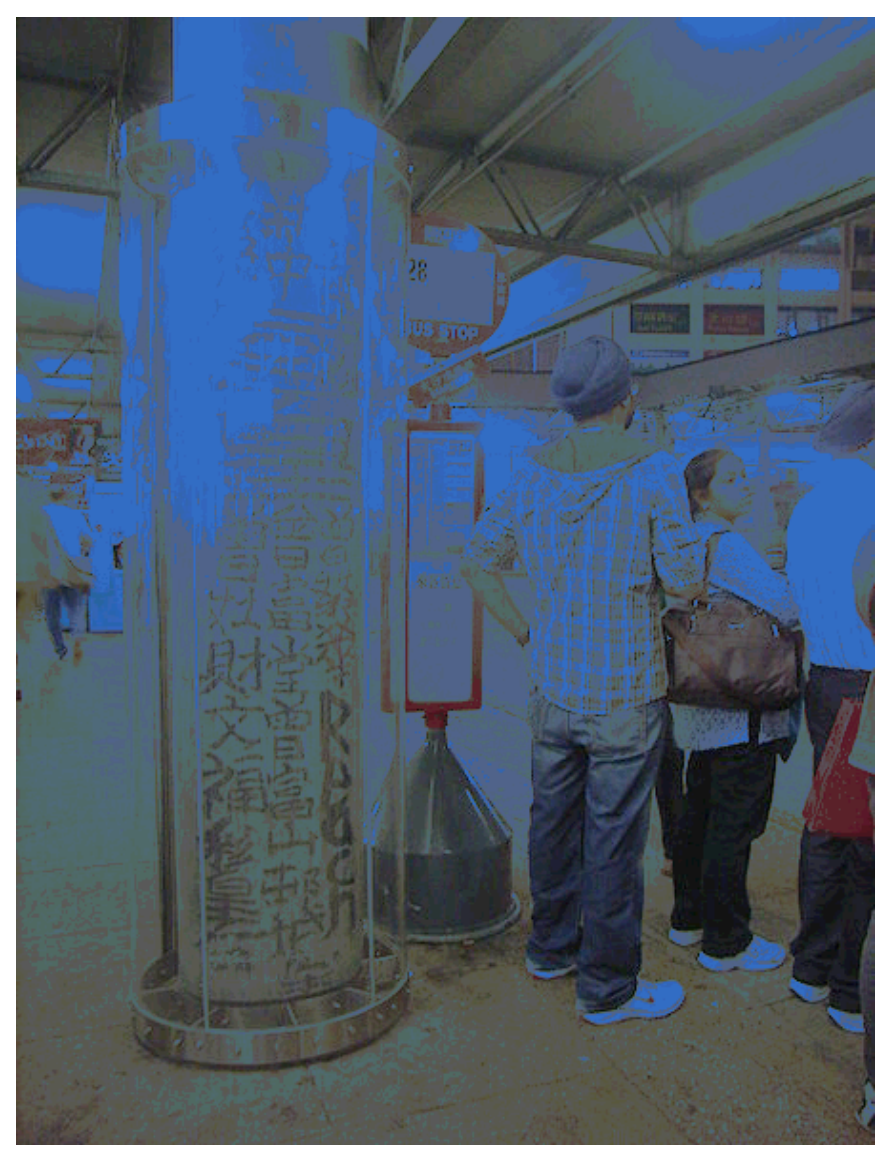

Figure 3. Tsang Tsou-choi's calligraphy on pillar, conserved under plexiglass, Star Ferry Pier, Tsim Sha Tsui, Hong Kong. 14 October 2009. Wikimedia Commons. 


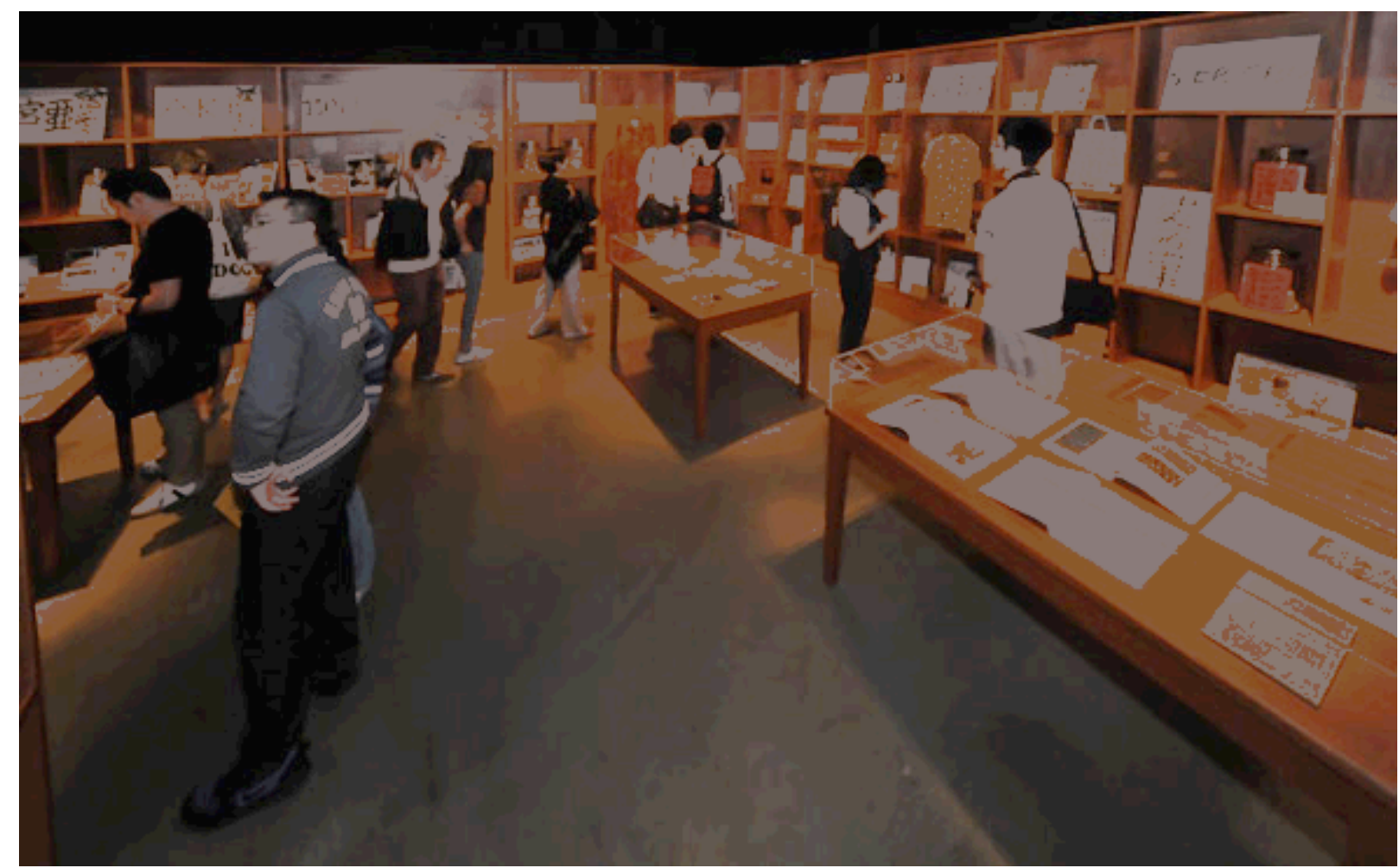

Figure 4. Exhibit view, 'Memories of King Kowloon.' ArtisTree, 20 April-31 May 2011, Hong Kong. Photograph by Swire Properties.

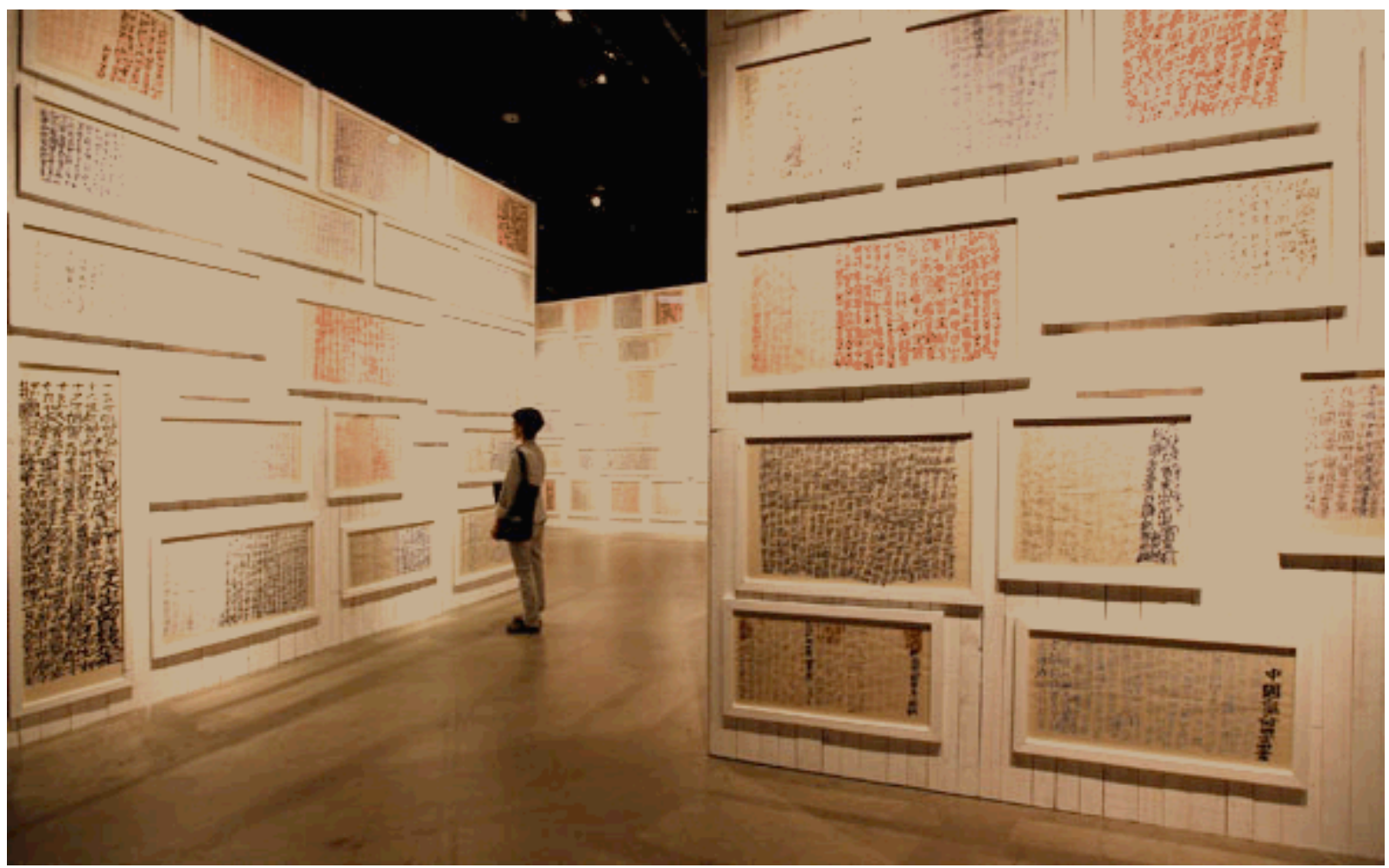

Figure 5. Exhibit view, 'Memories of King Kowloon.' ArtisTree, 20 April-31 May 2011, Hong Kong. Photograph by Swire Properties. 
work was also included in the Hong Kong exhibit of the 2003 Venice Biennale (see, for example, Lau 1997, 2000; Wear 1999; Chang 2001; Chung 2007, 2010). He has been featured in a variety of popular cultural productions, including a television documentary and commercial, and his calligraphy adorns various objects of mass produced consumer culture and daily life things, such as tea towels. Indeed, "[o]ver the past several years his work has been vigorously promoted, ripped-off and imitated by critics, serious artists and designers of fashion, CD's and bed linen" (Wear 1999: 93). The writing of Joyce Hor-Chung Lau, which regularly brings Hong Kong culture to the pages of The New York Times, succinctly captures the sweep of the art and culture world's appropriation of Tsang: 'A toothless garbageman who once wandered Hong Kong's streets with dingy bags of ink and brushes tied to his crutches is now the subject of a major retrospective' (Lau 2011). In October 2011, at the Sotheby's auction house in Hong Kong, a Tsang calligraphy on a utility box sold for HK\$650,000, a recordbreaking price for his work.

The name 'King of Kowloon' derives from the subjects of Tsang's calligraphic narratives and his textual personification as the descendent of a family whose lands in Kowloon were appropriated by the British colonial government. Indeed, the translation of the signature on Tsang's works, 九龍皇帝, is 'Emperor of Kowloon.' 'King of Kowloon' has the alliterative upper hand and reflects the monarchical titles of the British era, while the imperial code, 'emperor,' positions Kowloon as a Qing dynasty (1644-1911) place, a place in regional history before an era of nation-state politics. His stories include narratives referring to numerous family members, and recall a more settled sociality of family-based local relations. They suggest to me the idea of a refuge in textual form, in the face of hurtling modernization all around on the streets of Hong Kong. In our concern with understanding the city's elusive postcolonial condition, we may take a next step through the words of the art critic Eric Wear (1999: 3): "[i]n apparent abandonment of 'making sense' others find in him a sign of solidarity in the communal predicament"-in which the predicament must be the historically shifting situation of Hong Kong and its potential to destabilize place-based identity.

The iconicity of the 'King of Kowloon' in Hong Kong predates the commercialization of his work or any notion of auction prices. This history, I suggest, represents Rancière's distribution of the sensible, in the ways that Tsang enacted on the street the 
otherwise un-doable. Histories of Tsang always mention his crutches as if an accessory to his style en deshabille - a true sign of cultural monumentality — rather than reflecting on his extraordinary dedication to cultural production in the face of considerable hardship. Tsang arrived in Hong Kong from Guangdong at the age of 16, had limited education and lived his life in public housing estates. His waged job as a refuse site worker left him partially disabled from a leg injury and he subsequently negotiated some of the world's busiest streets on crutches. His dedication to a fully alternative life practice led his wife and children to abandon him: no wonder his writing recreates familial and state-society relationships. His process of transforming social isolation into public culture resonated in the life of the street, and he often returned to repaint sites where municipal workers had only just removed or painted over his brushwork (Chung 2007, 2011). His territorial practice in public space produced an estimated 55,000 calligraphies on urban outcrops around the city (Lau 2011), mostly in Kowloon.

The contradictions between Tsang's limited resources and power in the conventional sense and his adopted royal 'brush name,' between his apparently precarious condition and the regularity of his practice, and between his limited education and his adoption of a form of expression - calligraphy - that represents formal education — in addition to his cultural mien in contrast to his ultimate cultural status - together suggest some of the paradoxical conditions that characterize meanings of culture and the city in Hong Kong. In a city dominated by big banks and property development, and apparent endless concern with making money, these conditions of Tsang's practice and their symbolic meanings invert hierarchy, defy notions of status, problematize who produces cultureand uphold the significance of daily life experience in the face of an unknowable yet inevitable national future.

\section{Tang Chin}

By the second week of April 2011, stenciled likenesses of Ai Weiwei's face appeared around several of the major urban districts of Hong Kong, on nondescript walls, street surfaces, underground walkways and the occasional doorway. Their size was typically less than a meter and their locations tended to be relatively discreet (Figures 6 and 7). Despite their quiet appearance, without introductory fanfare, the stylized images, underscored by the caption, 'Who's Afraid of Ai Weiwei?,' became the focus of 

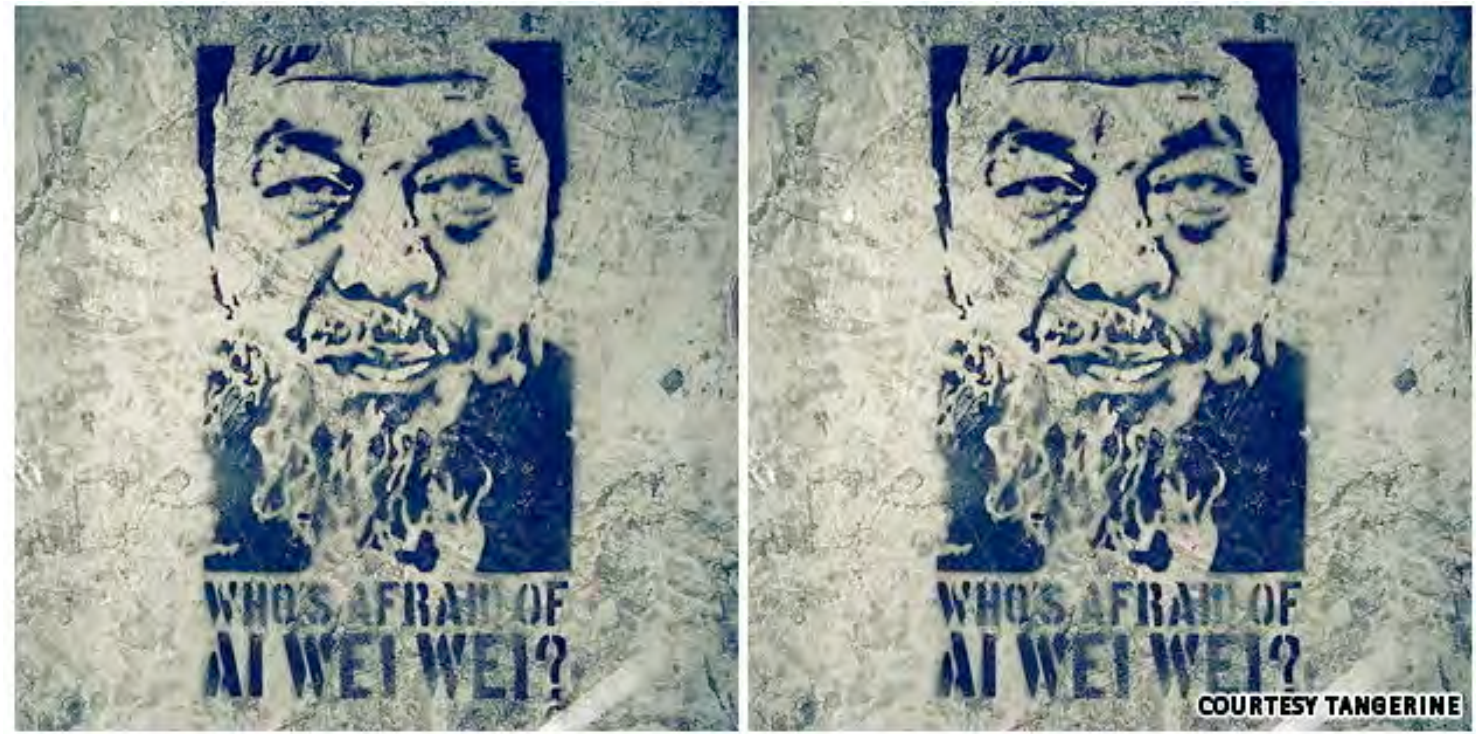

Figure 6. Stencil graffiti by Chin Tangerine. The first and most common design of several stenciled images used in the street art campaign for Ai Weiwei during April and May 2011 in Hong Kong.

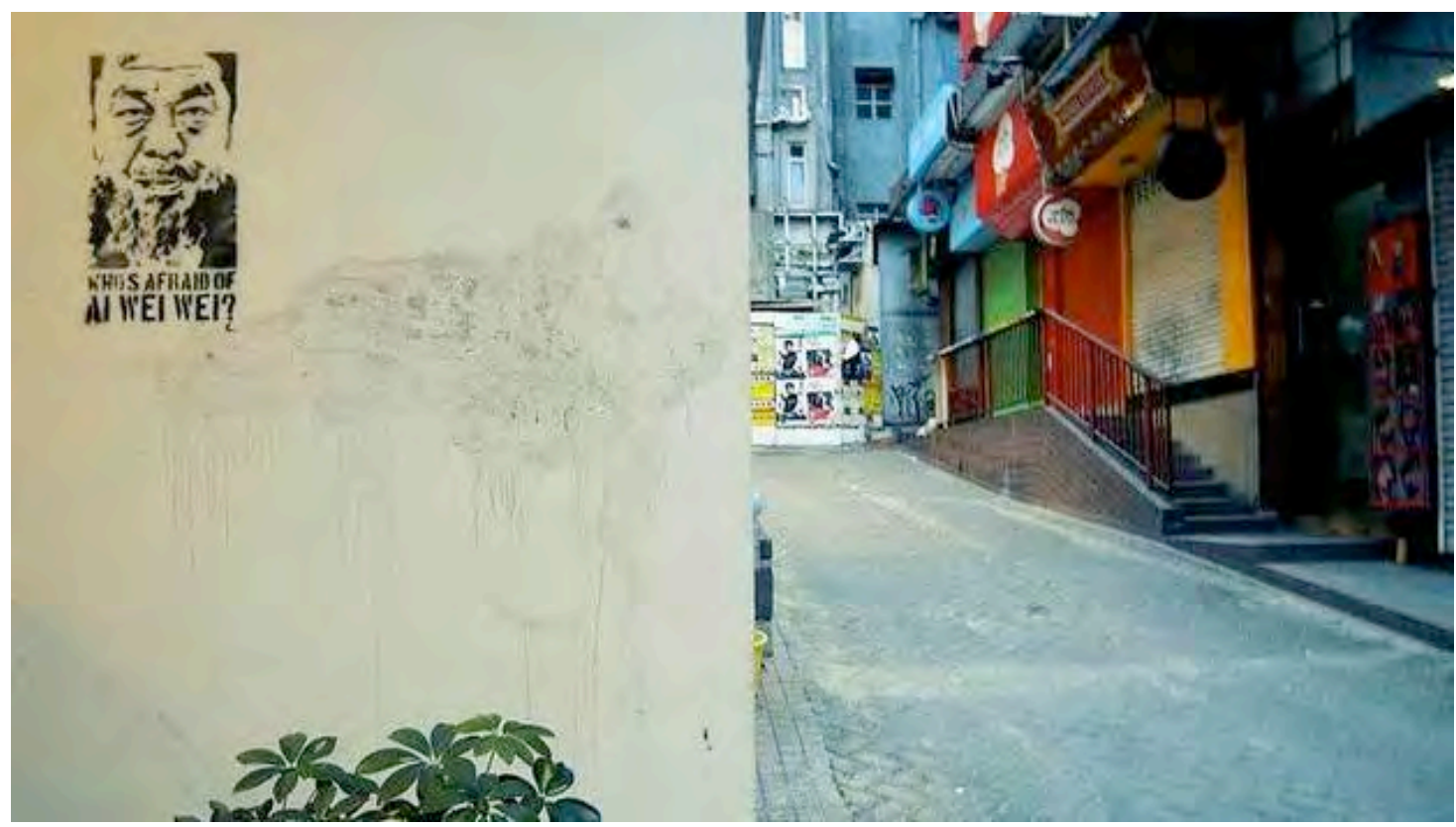

Figure 7: Back alley on Hong Kong island, 2011. Photo credit: Asia Art Archive.

intensive media interest and turned their creator, Tang Chin, as the Wikipedia entry for 'Free Ai Weiwei Street Art Campaign' notes, into 'an inadvertent cultural icon.' The unlikely emergence of a 22-year-old student and graffiti artist as the leading edge of what is now recorded as the campaign for Ai Weiwei in Hong Kong is inseparable from the contemporary era of the electronic circulation of the image. It is also, within the theoretical perspectives of Rancière, representative of the redistribution of the sensible: to place symbolic evidence in Hong Kong (of what is otherwise in Beijing); to make the disappearance of Ai Weiwei a subject of daily life encounter in the space of the city 
(what is otherwise understood as a verboten subject in the PRC), and, by posing 'Who's afraid of Ai Weiwei?,' to render thinkable that only one actor in the unfolding issue is afraid of Ai Weiwei (the governing regime).

The detention/abduction of Ai Weiwei without charge on April 3, 2011, at Beijing Capital International Airport, in addition to subsequent detentions of some of his colleagues, made any significant mention of Ai Weiwei, protest for him or tribute to him, seriously 'politically incorrect' in the PRC. Then what of the situation in the SAR, where freedom of speech is institutionalized in Article 27 of the Hong Kong Basic Law? The random and rapid appearance of the graffiti of Ai Weiwei's likeness in Hong Kong was met by unprecedented government effort to control it. Whereas paint graffiti on public or private property is a misdemeanor in Hong Kong, carrying a maximum penalty of a fine and three months' imprisonment, investigation of the graffiti was assigned to crime units (Apple Daily 2011; DeWolf \& Tsang 2001; NPR 2011; Tsang 2011; Wright 2011; Ye 2011). The regional crime unit investigates murder, rape and, not ironically, kidnapping. Treating graffiti as subject to criminal charges, carrying a maximum sentence of 10 years in jail, was unprecedented. In response to escalation of the investigation, the director of Hong Kong Human Rights Monitor observed: 'It is very clear that the police are under political pressure to pay special attention to the $\mathrm{Ai}$ Weiwei drawings' (Law cited in DeWolf \& Tsang 2011).

Vigorous state interest to control the proliferation and longevity of the image in public space impelled a quality of precariousness that engendered greater interest in its reproduction, and further resolve among artists, intellectuals, and political representatives concerned with Hong Kong's system of rights to prevail. The graffiti images by Chin Tangerine were the first among a larger set of public actions for $\mathrm{Ai}$ Weiwei in Hong Kong including additional graffiti, all manner of posters, light projections on building facades, public marches, and alternative performance art in public space (for example, see, Cheung \& Tsang 2011; Chow 2011; DeWolf 2011; DeWolf \& Tsang 2011; Sieh 2011; Tsang 2011; Wright 2011). People found they could download stencils of the images from the Internet and do-it-themselves on the street. The cycle of image production, chase and erase, fed the news cycle, which only intensified circulation of the images and propelled them into international interest. 
For example, within three weeks, on May 4, U.S. National Public Radio (NPR) program 'All Things Considered,' the daily afternoon news program covering 'the biggest stories of the day,' featured the street art campaign in the recorded broadcast 'Hong Kong Graffiti Challenges Chinese Artist's Arrest' (Lim 2011). Passers-by interviewed by NPR (2011) on location in Hong Kong pronounced the images 'cool': 'the graphic is cool and the presentation of protest against China is cool.' In response to a question about the criminal investigation of the graffiti, Tangerine replied, 'I have to thank them, the police, for drawing so much attention to this issue. Even if I have to go to jail it would be a very, very worthy price to pay.' At the time of this writing in February 2011, Tangerine's comments in the NPR interview are posted on dozens of cultural blog sites.

As the stenciled likeness of Ai Weiwei proliferated, Ming Pao (明報), Hong Kong's leading Chinese language newspaper, suggested that the proliferation of the graffiti in particular sites triggered escalation of the police investigation (Ye 2011). 'Dozens' of new Ai Weiwei graffiti appeared during mid-April 2011 in the city's most highly trafficked pedestrian locations, locations that are emblematic of the elite state-capital alliance in Hong Kong, especially the International Commerce Centre, the financial heart of the city, and the Star Walk, a primary destination of Mainland tourists on the Kowloon-side Tsim Sha Tsui waterfront. Under the headline “什麼人訪問什麼人: 我的塗 鴉 最想給內地人和銀行家看' (Who Visits Who: I'd Like to Give Mainlanders and Bankers a Look at My Graffiti), Ming Pao published a 3500-character interview with “塗鴉少女' (graffiti girl) that contextualizes the street art campaign in the context of concerns for the larger Hong Kong social movement, the increasing citizen surveillance by the state, and the need to maintain and nurture social justice in the city (Ye 2011).

Asked by the media to explain why she undertook the street art project, Tang (in deWolf \& Tsang, 2011) explained, 'I'm not very politically sensitive normally, but this really touched some core values - there's a line that should not be crossed.' Both the SAR and PRC governments use 'core values' to transmit governing ideology and contour statesociety relations in philosophical terms. For example, the Chinese Communist Party promoted 'core values' in 2006 as the 'moral and ideological foundation' of the 'socialist harmonious society' platform introduced under Hu Jintao. In contrast with the PRC, Hong Kong SAR core values include freedom of expression and the rule of law. By adopting a first person perspective on 'core values,' her statement repositioned 
'values' as a discourse available to anyone, and in mirroring state discourse, achieved a critical rhetoric that points to hypocrisies of government policies and state notions of moral standards.

\section{Concluding perspectives}

The street art campaign for Ai Weiwei and the street calligraphy by Tsang Tsou-choi demonstrate forms of local legibility in Hong Kong. Each symbolizes a set of statesociety relations in the public interest through visual media as a basis for symbolic politics. Each has produced images generating negotiation-between the artist/cultural worker/citizen provocateur and the government, and among people in all walks of life as they circulate in society. The well-known history of the street calligraphy of the King of Kowloon demonstrates how local outlooks have accommodated and understood provocative and polemical graffiti as outlets for social and political sentiment. The street art campaign for Ai Weiwei effectively bridged the inequality gap: the investment banker going to work at the International Financial Centre would be reminded of $\mathrm{Ai}$ Weiwei's disappearance while so would the street cleaner dispatched to an underground pedestrian walkway to remove the paint. At Star Walk many tourists from the PRC would be compelled to inquire, who is the man in this image?

These projects enacted in the public life of the city contrast with ideas about culture in terms of 'disappearance.' We may find a 'culture of disappearance' if we understand the circulation of Tsang's and Chin's works through their reproduction as images and their ultimate disappearance in the space of the city. Yet I find it more relevant to understand the circulation of these works and images of them through a logic of precariousness in which the meaning of precariousness holds together concerns about state-society relations, income inequality and the condition of postcoloniality in Hong Kong, a condition that is always ever fleeting. Certainly the idea of disappearance 'disappearing' the city is wholly untenable. I would suggest instead that Tsang's and Chin's works in fact urge us to consider the significance of daily life in the city in all its appearances, and, in learning from difference and difference in identify formation, to reach for political-ethical understandings of social life and cultural production.

The crossover of these cultural projects - between graffiti, street art, art action, alternative performance art, political protest and rights campaign - and their multiple media of expression exemplifies qualities of the 'distribution of the sensible.' Jacques 
Rancière's understanding of the aesthetic regime-its collapse of medium specificity and its challenges to 'art,' in the normative sense, as a distinct practice-identifies the significance of art and cultural practice before and outside the market. His articulation recognizes diverse cultural projects in the world today whose products and material outcomes are not readily identifiable as 'art' in a public sphere that has been socialized by normative state discourses of 'creative industry,' that is, an expectation of 'culture' in saleable forms. His articulation recovers the distance between historic culturalpolitical movements of avant-gardes and places of the present where complex human issues need to be addressed. Certainly this understanding complicates who is an artist in the world today. It relieves the discipline of art history as final arbiter, and returns the idea of art to people whose cultural projects take shape in multiple contexts, dimensions and sensoria. In the contemporary neoliberal world economy, any cultural project that effectively resists the bounds of the art system has become a political project.

The enduring significance of Tsang Tsou-choi's practice in the daily life of urban Hong Kong continues to resonate in a city whose collective identity seeks to write its own history. The predictable commodification of his graffiti works subsequent to his death contrasts to reactions to the stenciled graffiti of Ai Weiwei on the street. In the same city at the same time, one alternative cultural practice received valorization and acclaim, while the other, in public space, antagonized the state and drew police interest to criminalize the activity. The police logic would seek to convey to the public that something is 'wrong' with Ai Weiwei and that something is wrong with supporting him. However, in the context of the broader Hong Kong social movement, the logic works to opposite outcomes: if there is freedom of expression in Hong Kong, then 'who' is criminalizing the graffiti? If a graffito caption is in English in Hong Kong, who is the intended audience and what are the implications? Certainly the issue deserves more analysis than this brief treatment, including the future of these images of Ai Weiwei. Already most of the images from the campaign that were circulating on the Internet have been taken down or copyrighted.

The circulation of the image in the context of contemporary globalization breaks the historic logic that the ephemeral is not cultural because it is not durable; and in recognizing the instabilities of the present, identifies hegemonic political economic logics and seeks modes of resistance. Within these perspectives, the works of Tsang and 
Tang exemplify the potential of the image to contain and hold complex understandings of political and economic exigencies. In Hong Kong as a place that mastered rapid production for the world economy and then bequeathed its manufacturing apparatus, after 1979, to the PRC, Hong Kong as a global city - a center of 'flows' - is a pivotal site of the production and relay of images. It has also become, paradoxically, a center of arbitration over what is culture and cultural production in China.

\section{Reference List}

Abbas, A. 1997, Hong Kong: Culture and the Politics of Disappearance. University of Minnesota Press, Minneapolis.

Apple Daily (蘋果日报) 2011, “少女涂鸦撑艾未未 重案组政治大搜捕’ (Graffiti Girl Supports Ai Weiwei; Crime Unit's Big Political Search), 15 April. Online, available: http://hk.apple.nextmedia.com/news/art/20110415/15169662 [Accessed 1 January 2012].

Chang, T. Z. 2001, 'King of Kowloon (Tsang Tsou-choi),' in Power of the Word. Independent Curators International, New York: 32.

Chow, V. 2011, 'Artists to Hold Shows in Support of Ai Weiwei,' South China Morning Post, 19 May. Online, available: http://www.scmp.com/article/968145/artists-hold-shows-support-ai-weiwei [Accessed 1 January 2012].

Chung, J. et al. 2007, 九龍皇帝. 2, 禁止標貼 = The Art of Treason. 2, Post No Bill. CUP Magazine, Hong Kong.

Chung, J. 2010, Kowloon King. Asia One, Hong Kong.

Clarke, D. 2001, Hong Kong Art: Culture and Decolonization. Duke University Press, Durham, NC.

Corcoran, S. 2010, 'Editor's Introduction,' in Dissensus: On Politics and Aesthetics, J. Rancière. Continuum, London: 1-24.

DeWolf, C. 2011, 'Hundreds March in Support of Detained Artist Ai Weiwei,' South China Morning Post, 24 April. Online, available: http://www.scmp.com/article/965919/hundreds-march-supportdetained-artist-ai-weiwei [Accessed 1 Janurary 2012].

DeWolf, C. \& Tsang, P. 2011, 'Ai's Arrest Crossed a Line, Says Graffiti Artist,' South China Morning Post, 16 April. Online, available: http://www.scmp.com/article/965198/ais-arrest-crossed-linesays-graffiti-artist [Accessed 1 January 2012].

Erni, J. N. 2001, 'Like a Postcolonial Culture: Hong Kong Re-imagined,' Cultural Studies, vol. 15, no. 34: 389-418.

Erni, J. N. 2012, 'Who Needs Strangers? Un-imagining Hong Kong Chineseness,' Chinese Journal of Communications, vol. 5, no. 1: 1-10.

Fu, P. 2003, Between Shanghai and Hong Kong: The Politics of Chinese Cinemas. Stanford University Press, Stanford, CA.

Henderson, J. C. 2008, 'Conserving Hong Kong's Heritage: The Case of Queen's Pier,' International Journal of Heritage Studies, vol. 14, no. 6: 540-54.

Ho, O. 2005, 'The Problem with Politics: An Interview with Oscar Ho,' (by J. Millichap), Yishu: Journal of Contemporary Chinese Art, vol. 4, no. 4: 10-13.

Jacobs, J. M. 1996. Edge of Empire: Postcolonialism and the City. Routledge, London.

Lo, S. H. H. 2010, Competing Chinese Political Visions: Hong Kong vs Beijing on Democracy. Praeger, Westport, CT.

Lau, J. H. C. 2011, 'King of Kowloon Finally Gets Respect,' New York Times, 4 May. Online, available: http://www.nytimes.com/2011/05/05/arts/05iht-kowloon05.html?pagewanted=all\&_r=0 [Accessed 1 January 2012].

Lau, K. W. (ed.) 1997, The Street Calligraphy of Tsang Tsou Choi. Kin Wai's Workshop, Hong Kong. 2000, 'Tsang Tsou Choi,' in Artscope Hong Kong 2000. Exhibition catalogue, Sabrina Fung Fine Arts, Hong Kong: n. p.

Lim, L. 2011, 'Hong Kong Graffiti Challenges Chinese Artist's Arrest,' National Public Radio. Online, available: http://www.npr.org/2011/05/04//135985475/hong-kong-graffiti-challenges-chineseartists-arrest [Accessed 1 January 2012]. 
Lu, T. L. D. 2009. 'Heritage Conservation in Post-colonial Hong Kong,' International Journal of Heritage Studies, vol. 15, nos. 2-3: 258-72.

Ngan, I. and Lai, E. (eds.) 2004, Mapping Identities: The Art and Curating of Oscar Ho. Para/Site: Hong Kong.

Rancière, J. 2007, 'Art of the Possible,' Interview with J. Ranciere by F. Carvevale and J. Kelsey, Artforum, vol. 45, no. 7: 256-67. 2009, Aesthetics and its Discontents, trans. S. Corcoran. Polity Press, Cambridge.

Sieh, M. 2011, 'Finding a Voice in Art,' South China Morning Post, 30 May. Online, available: http://www.scmp.com/article/969147/finding-voice-art [Accessed 1 January 2012].

Smith, T. 2008, 'Introduction: The Contemporaneity Question,' in Antinomies of Art and Culture, (eds) T. Smith, O. Enwezor \& N. Condee, Duke University Press, Durham, NC: 1-19.

Tam, S. M. 1997, 'Eating Metropolitaneity: Hong Kong Identity in Yumcha,' The Australian Journal of Anthropology, vol. 8, no. 3: 291-306.

Tsang, P. 2011, 'Ai Weiwei Backers Project Graffiti Image onto Landmark Buildings,' South China Morning Post, 29 April. Online, available: http://www.scmp.com/article/966332/ai-weiweibackers-project-graffiti-image-landmark-buildings [Accessed 1 January 2012].

Virilio, P. 1991, The Aesthetics of Disappearance. MIT Press, Cambridge, MA.

Wear, E. 1999, 'No Place is Home: Outmanoeuvring Cultural/Racial Identity in Hong Kong,' in Hong Kong Art Review, (eds) E. Wear \& O. Ho. International Association of Art Critics, Hong Kong: 80-93.

Wright, A. 2011, 'The Buzz,' South China Morning Post, 5 May. Online, available: http://www.scmp.com/article/966821/buzz [Accessed 1 January 2012].

Ye Bolin (葉寶琳) 2011, “什麼人訪問什麼人:我的塗鴉 最想給內地人和銀行家看’ (Who Visits Who: I'd Like to Give Mainlanders and Bankers a Look at My Graffiti), Ming Pao [Hong Kong], 24 April. Online, available: https://ol.mingpao.com/cfm/style5.cfm?File=20110424/sta13/vza2.txt [Accessed 1 January 2012]. 